\title{
Supporting Online Faculty through a Sense of Community and Collegiality
}

\author{
Aimee LaPointe Terosky \\ Saint Joseph's University \\ Chris Heasley \\ Drexel University
}

\begin{abstract}
In this qualitative study, we examine the experiences of seven tenure-track and non-tenure track current/future online faculty through the conceptual lenses of sense of community (McMillan \& Chavis, 1986) and collegiality (Gappa, Austin, \& Trice, 2007). We found: (1) participants reported that their sense of community and collegiality around online course development and teaching was lacking, (2) participants' communities for online teaching, if available, primarily focused on technical support, and (3) participants desired greater community and collegiality for philosophical and psychological concerns with the medium of online teaching. We conclude with recommendations for practice for online faculty professional growth.
\end{abstract}

\section{Introduction}

With an increase in the number of online courses being offered in higher education, college and university faculty face growing pressure to develop and teach online courses (Allen \& Seaman, 2011, 2013). As a result, we ask 'How are faculty being prepared for this professional endeavor?' The past two decades have seen significant growth in the creation of teaching and learning centers and professional development offerings for online faculty, as well as knowledge-sharing consortiums, recognition programs for exemplary models (e.g., Sloan-C Excellence in Faculty Development for Online Teaching), and scholar/practitioner journals dedicated to online education (Meyer \& Murrell, 2014). Yet, despite this noted progress, a majority of faculty remains dissatisfied with their institution's support for professional development in online teaching. In a survey of 10,700 faculty members from 69 colleges and universities 
across the United States, Seaman (2009) reports that the vast majority of faculty participants described their institutions as below average in providing support and incentives for online teaching (see Herman, 2012) and $19 \%$ of the institutions had no professional development offerings specific to online teaching (see Allen \& Seaman, 2010). Moreover, scholars and practitioners in the field of faculty development question the effectiveness of some of the current approaches to professional development for online teaching along three lines: its reliance on "one-shot" workshops, its focus on content-neutral training on technology tools, and its lack of collaborative learning communities (Hollenshead, Waltman, August, Miller, Smith, \& Bell, 2007; Koehler, Mishra, Hershey, \& Peruski, 2004; Sherer, Shea, \& Kristensen, 2003). The latter is the focus of this article.

To define a collaborative learning community, we borrow from Fulton and Riel: "a group of individuals who are interested in a common topic or area and who engage in knowledge-related transactions as well as transformations within it” (1999, p. 8). Extant literature on academic careers highlights the significance of collaborative learning communities for faculty professional growth, motivation, teaching effectiveness, job satisfaction, and retention (Cox, 2004; Gappa, Austin, \& Trice, 2007; Haviland, 2011; Neumann, 2009; O’Meara, Terosky, \& Neumann, 2008; Puzziferro \& Shelton, 2009; Rice, Sorcinelli, \& Austin, 2000). In their faculty professional growth model, O’Meara, Terosky, and Neumann (2008) include professional relationships as one of four key tenets, largely because professional relationships "stimulate, facilitate, and shape learning" and "strengthen[s] faculty capacity to bring the best of their talents to their work roles" (p. 29). Specific to online education, studies on faculty preferences for professional development for online teaching highlight that community/collegialityrelated offerings ranked high among faculty, in particular opportunities for mentoring and learning with peers (Gilbert, 1995; Herman, 2012; Kinuthia, 2005). A study of 328 online professors at 12 randomly selected community and technical colleges in the state of Washington found $87 \%$ of participants (regardless of gender, appointment type, age, experience with online teaching, and discipline) ranked interacting with other faculty on issues around online teaching as valuable (Maier, 2012). Similarly, work by Lu, Todd, and Miller (2011) highlighted that learning communities created supportive environments for faculty experimentation with teaching with technology.

Although institutions, especially research/doctoral universities and community colleges, are increasingly offering professional development opportunities geared toward learning communities (Meyer \& Murrell, 2014), collaborative learning communities are not a common practice on higher education campuses (Velez, 2009), largely due to time- and resource-related constraints. As such, the majority of faculty report unsatisfactory levels of collegial interaction at their institutions (Gappa et al., 2007; Haviland, 2011; Helms, 2010; Kezar, 2012), especially online faculty who are often physically separated from colleagues and students due to the nature of online courses (Dolan, 2011; Glass 2012; Haber \& Mills, 2008; McLean 2006; Maier, 2012) and non-tenure track/adjunct faculty who garner fewer professional networks because of their lack of involvement in shared governance, reduced time on campus (Kezar, 2012; Maier, 2012), and high teaching loads (Meyer \& Murrell, 2014).

In light of expert recommendations for promoting collaborative learning communities among faculty, as well as the challenges of doing just that among online faculty, we turn to two conceptual frameworks, sense of community and collegiality, to better understand the perspectives and experiences of faculty who currently teach online courses or who indicate an interest in learning more about online education. Specifically we asked two questions:

1. Do participants perceive a sense of community and collegiality around online course development and teaching?

- If yes, in participants' perspectives, what does the community provide in terms of online course development and teaching? 
2. According to participants' points of view and experiences, would they benefit from a sense of community/collegiality around their current/future/potential online course development and teaching?

- If yes, how so?

\section{Conceptual Frameworks}

This study is grounded in the conceptual frameworks of sense of community and collegiality. Sarason (1974) defined sense of community as the sense that one is a part of a larger "mutually supportive network of relationships" (p. 1). McMillan and Chavis (1986), whose framework remains the most widely used for sense of community research, defined it as "a feeling that members have of belonging, a feeling that members matter to one another and to the group, and a shared faith that members' needs will be met through their commitment to be together” (p. 9).

Operationally, the McMillian and Chavis (1986) framework is comprised of four elements: membership, influence, reinforcement of needs, and shared emotional connection. The first element, membership, is grounded in personal ownership and investment with the community, thereby establishing boundaries that provide a safe environment in which members are able to be emotionally vulnerable. The second element, influence, is defined as a reciprocal relationship that provides a sense of mattering, in which members feel as though they are contributing to the community while the community is also influencing them. The third element, reinforcement of needs, highlights that the integration and fulfillment of individual and community needs is a requirement for a sense of togetherness within a community construct. The last element, shared emotional connection, is the "commitment and belief that members have shared and will share history, common places, time together, and similar experiences" (McMillan \& Chavis, 1986, p. 9).

A second conceptual framework guiding our study is collegiality, which is a commonly used construct in the higher education literature. In defining collegiality, we rely on Gappa, Austin, and Trice (2007): collegiality is faculty members' ability to belong to a community of colleagues who value their contributions to the institution. It highlights opportunities for faculty members to learn from one another by having a sense of belonging and inclusion (see also Kezar, 2012). Resonating with the conceptual framework of community of practice, learning is viewed as a cognitive act situated within social interactions and communities rather than individually acquired (Brown, Collins, \& Duguid, 1989; Lave, 1997; Vygotsky, 1978; Wenger, 1999). "Social interactions with significant others and membership in groups” writes Glass, “are not peripheral forces influencing a person's actions; they are generative forces involved in the very production of a person's activities and ways of making meaning of the world” (2013, p. 6).

In their research-based framework for essential elements for effective faculty work, Gappa et al. (2007) included collegiality alongside equity in academic appointments, academic freedom, ensuring flexibility in academic appointments, and professional growth. They argue that if these five essential elements are in place, there are numerous positive outcomes for faculty work, including: "increased satisfaction, a sense of meaningfulness, increased commitment to organization, enhanced recruitment and retention, broader spectrum of individuals represented on the faculty and more strategic utilization of intellectual capital” (in Kezar, 2012, p. 10).

The complementary conceptual frameworks of sense of community and collegiality ground this study of current and future online faculty members as we strive to better understand how to support all faculty engaging in online education. We use the concept of sense of community to concentrate on faculty perceptions around their network of supportive relationships, while the concept of collegiality hones in on faculty-to-faculty interactions, which is a shared value in academia. 


\section{Methods}

This qualitative study follows in the tradition of narrative inquiry (Vogt, Gardner, \& Haeffele, 2012). We examined seven faculty members' perceptions of sense of community and collegiality around online course development and teaching. The research site, Metropolitan University (MU) (a pseudonym), is a private university located in a major metropolitan area. With an undergraduate and graduate student population in excess of 7,000, MU employs more than 300 tenure-track faculty and 350 non-tenure track faculty. We selected MU for a number of reasons: (a) its significant increase (approximately 100 percent growth) in online course offerings over the past five years due to market forces and/or mandates from upper-and-middle level administrators, (b) its mission statement and institutional culture prioritizing and rewarding effective teaching and concern for students, (c) its historical and rigorous face-to-face liberal arts education program, (d) its reliance on faculty to develop and teach online courses in a relatively limited academic technology infrastructure, and (e) its desire to evolve its faculty development program to better support online faculty. ${ }^{1}$ We believe that MU contains characteristics relevant to other institutions of higher education, especially institutions with limited resources (i.e., budgets, personnel) for faculty development in online teaching and/or institutions without a history in online education.

\section{Participants and Data Collection}

Although MU has significantly increased its online offerings over the past five years, the majority of faculty are characterized as cautious about online education and only approximately $15 \%$ have developed or taught an online course. With continued pressure on MU faculty to develop and/or teach online courses, we decided to follow purposeful sampling methods (Creswell, 2012) by targeting faculty members indicating experience or interest in online education in hopes of learning if and how they feel supported in their online efforts. As such, we drew our participant sample from a list of 12 faculty members who attended a voluntary MU sponsored professional development workshop on best practices in online education ${ }^{2}$ offered two weeks after the end of a spring semester. We emailed all 12 faculty members in attendance inviting them to participate in our research study and seven agreed to participate. Our sample of seven includes a diverse range in appointment type (three full-time faculty and four parttime/adjunct faculty), experience in teaching at the higher education level (ranging from one to more than 25 years), and experience with online course development and teaching (ranging from zero to six years) (See Table 1 below for participant demographics). Except for an annual one-day conference on teaching with technology that draws a larger crowd, the sample size of this study is representative of the typical attendance at MU's online faculty development workshops and programs.

\section{Analysis and Trustworthiness}

We followed a manual coding process (Saldaña, 2012) through which we read transcripts independently and identified relevant areas of the transcripts where faculty spoke about sense of community/collegiality in online course development and teaching. Throughout our reading of the

\footnotetext{
1 At the time of data collection, MU's faculty development offerings for online teaching primarily included: half-day workshops and online modules on the course management system and its tools, instructional design consultations, annual (one day) conference on teaching and learning with technology, innovation grants, and support for technology in the face-to-face classroom setting.

2 The one-day workshop agenda covered the following topics: instructional design, strategies for online course management, online tools and best practices, and support services for online education at MU.
} 
transcripts, we asked ourselves the following analytical questions: (a) Do faculty members talk about a sense of community/collegiality around online course development and teaching, and if so, how do they do so? (b) If applicable, what do faculty discuss as sources of support (or lack of support) for their current or future involvement in online education? (c) Do faculty share what areas of online education they feel the most in need of support through a sense of community/collegiality? We developed a list of potential code names to describe common ideas and actions. After reading and notating transcripts independently, we jointly developed a master code-list that we used for subsequent coding cycles. In latter coding cycles, we read across the transcripts to combine common codes in order to develop more robust themes. The final step in our analysis was to examine our codes and themes according to variables among our participant pool, including appointment type, gender, and years of experience with teaching and online education.

We used five strategies to enhance the trustworthiness of this work (Vogt et al., 2012). First, two of us (multiple investigators) were involved in conceptualizing this study. Second, a graduate research assistant, who transcribed the interviews, acted as a critical friend in the analysis. Third, we shared our work with three noted scholars and/or practitioners of online education during our analysis stage. Lastly, we displayed quotes from the participants, as much as possible based on page limitations, in order to allow readers to develop a sense of the data and participants. Despite our focus on trustworthiness, this study has limitations related to sample size and therefore we do not strive for generalizability. Instead, we strive for a discussion of meaningful concepts (Erickson, 1985) that emerged from the perspectives and actions of a group of faculty characterized as engaged in online education - or those with a willingness to learn more about online education - in hopes of creating valuable frameworks that may guide scholars, practitioners, faculty members, and staff developers of online education.

\section{Findings}

\section{Participant Variables}

As previously mentioned, we followed purposeful sampling methods in that we invited faculty members who demonstrated an interest in online education by their attendance at a voluntary workshop. Our sample of participants held a number of variables in terms of discipline, years of experience, and appointment type. Following our analysis, we noted that the most consistent variation in responses among the participants related to appointment type, specifically differences about perceived sense of community/collegiality between those employed full-time and those employed part-time, as well as those with more years of experience with online education. Throughout our findings, we note variations among participant sample variables when highlighting the themes that emerged from our analysis.

\section{Perceptions of Sense of Community and Collegiality}

In this study, we had two inquiries. The first questioned if participants perceived a sense of community and collegiality around online course development and teaching, and if they did, in what ways did they benefit. In response, both the full-time and part-time participants noted that a sense of community and collegiality around online teaching was lacking. Full-time faculty described their current online course development process as one in which they are primarily "on [their] own." However, they noted that, if desired and self-initiated, they could leverage their established networks of colleagues for assistance with their online courses, albeit this assistance typically revolved around "technology help."

Part-time participants not only felt that a sense of community and collegiality around online teaching was lacking, but argued it was essentially non-existent. When asked to describe their process for their current/future online course preparation, part-time participants used language such as "left to your own devices," "trial by fire,” "sink or swim,” and “out of the loop.” "I don’t think” shared Ben, a part- 
time faculty member with experience teaching online, "there is a great community of online people that I could turn to." Evident in the voices of part-time participants is a frustration with the lack of even a minimal level of support from their colleagues, similar to trends in the extant literature on the experiences of non-tenure track/adjunct faculty (Kezar, 2012).

Table 1 Demographics of Participants

\begin{tabular}{|c|c|c|c|c|c|c|}
\hline Pseudonym & Gender & Discipline & $\begin{array}{l}\text { Appointment } \\
\text { Type }\end{array}$ & $\begin{array}{l}\text { Years of } \\
\text { Teaching } \\
\text { (f2f) } \\
\text { Experience }\end{array}$ & $\begin{array}{l}\text { Number of } \\
\text { Online } \\
\text { Courses } \\
\text { Developed }\end{array}$ & $\begin{array}{l}\text { Number of } \\
\text { Online Courses } \\
\text { Taught }\end{array}$ \\
\hline Charlie & Male & $\begin{array}{l}\text { Humanities/Social } \\
\text { Sciences }\end{array}$ & $\begin{array}{l}\text { Full-time, } \\
\text { Non-tenure } \\
\text { track }\end{array}$ & $25+$ years & One & Zero \\
\hline Ben & Male & Applied & $\begin{array}{l}\text { Part-time } \\
\text { adjunct, Non- } \\
\text { tenure track }\end{array}$ & 5-9 years & One & $\begin{array}{l}\text { One course for } \\
\text { one year }\end{array}$ \\
\hline Leslie & Female & $\begin{array}{l}\text { Humanities/Social } \\
\text { Sciences }\end{array}$ & $\begin{array}{l}\text { Full-time, } \\
\text { tenure track, } \\
\text { Associate } \\
\text { Professor }\end{array}$ & 10-14 years & One & $\begin{array}{l}\text { One course for } \\
\text { six years }\end{array}$ \\
\hline Maggie & Female & Sciences & $\begin{array}{l}\text { Part-time } \\
\text { adjunct, Non- } \\
\text { tenure track }\end{array}$ & $1-4$ years & Zero & Zero \\
\hline Nolan & Male & $\begin{array}{l}\text { Humanities/Social } \\
\text { Sciences }\end{array}$ & $\begin{array}{l}\text { Part-time } \\
\text { adjunct, Non- } \\
\text { tenure track }\end{array}$ & $25+$ years & Zero & Zero \\
\hline Olivia & Female & Applied & $\begin{array}{l}\text { Part-time } \\
\text { adjunct, Non- } \\
\text { tenure track }\end{array}$ & $1-4$ years & Zero & Zero \\
\hline Thomas & Male & $\begin{array}{l}\text { Humanities/Social } \\
\text { Sciences }\end{array}$ & $\begin{array}{l}\text { Full-time, } \\
\text { tenure track, } \\
\text { Associate } \\
\text { Professor }\end{array}$ & $25+$ years & Two & $\begin{array}{l}\text { Two courses } \\
\text { for five years }\end{array}$ \\
\hline
\end{tabular}

For data collection, we conducted 60-90 minute semi-structured interviews with each of the seven participants. The interviews consisted of four major sections. First, we began conversationally with "grand-tour questions" (Spradley, 1976) concerning the faculty members' entrances into higher education and face-to-face, hybrid, and/or online teaching. Then, we inquired about their philosophy of education, before moving on to how each develops their face-to-face, hybrid, and/or online courses. We concluded with questions related to their assessment of support and sense of community/collegiality around online course development and teaching. All interviews were recorded and transcribed. In addition, we reviewed relevant documents when made available by the participants, including curricula vitae, syllabi, and face-to-face or online course materials. 
Like the full-time faculty, the onus rested with the part-time faculty members, and in turn, they had to self-initiate pathways to learn about and/or improve their skill set around online teaching, with the most common strategies being personally paying for and completing courses on online pedagogy and technology, reading books about online pedagogy and technology, seeking feedback from external networks or students, and attending technology workshops sponsored by MU.

In summary of our study's first question, all of the participants agreed that a sense of community and collegiality around online course development and teaching was lacking, especially so for part-time participants. If participants received support in regard to their current/future online development and teaching experience, it was self-initiated and focused on technology skills. Despite the limited range of perceived support, participants welcomed opportunities for increased interactions with colleagues around online teaching. Next, we share findings on our study's second question, which directly and indirectly explored participants' perspectives on how they might benefit from a sense of community around online teaching.

\section{Perceived Benefits of a Sense of Community/Collegiality}

In-depth analysis of participants' narratives revealed that areas beyond technical skills-needs of a philosophical or psychological nature-were pressing in their reflections about online teaching. As such, participants significantly desired a community of colleagues in which to grapple with these issues, challenges, and opportunities. This is not to suggest participants did not value the available technical assistance, largely in part because technology skills are such a basic need for an online educator, but it does suggest participants had other needs that warranted attention. In this next section, we lay out our key findings in this regard, which included: (a) philosophical questions around the nature of online courses, and (b) professional work and identity issues regarding the changing nature of the teaching aspect of professorial work.

Philosophical questions around the nature of online courses. All participants except one were willing to teach online. The lone outlier, Nolan, a part-time faculty member, conducted extensive research on online courses (e.g., attended professional development workshops on online education, read books and articles about online education, audited a colleague's online course) and determined that at his "stage of life" he had the option to refuse to move his teaching to an online format. Despite their willing dispositions (and unwillingness in the case of Nolan) toward online course development and teaching, participants commonly questioned online teaching at a philosophical level.

This questioning can first be seen in the origins of participants' involvement in online courses. They became interested in online education or began developing and teaching online courses for pragmatic reasons, such as current economic contexts and/or student trends, rather than viewing it as a superior form of teaching or as a "burning desire" to engage in this method of instructional delivery. Most of the participants realized online courses were the "way of the future" and therefore decided to "get on the train" out of necessity. "I see a lot of the education here [at MU] going online," reflected Olivia, a part-time faculty member, "So I didn't want to become a dinosaur teaching a class." Similarly, Thomas explained his reasons for adopting online education by sharing, "It's the way of the future in adult education and it is an accommodation to the kinds of students that need the convenience of online education because of their lifestyles." Leslie, a full-time faculty member, explained, "Online is here to stay and there is not really a choice per se and I don't think departments and the university [are] doing enough on sending that message to teachers." The impetus for participants' involvement in online education is important; their initial reasons for adopting online education speaks to pragmatics rather than to philosophical alignment. More so than traditional, face-to-face teaching, most participants were still in flux as to whether their educational philosophies were in agreement with the structure of online teaching, 
and therefore they were in the process of reconciling their own preconceived notions about the value of such.

Charlie's case speaks clearly to this issue. Charlie, a full-time faculty member who is currently developing his first online course, values multi-sensory and multi-modality forms of teaching and he greatly questions if the atmosphere created in his classroom could be projected online. Moreover, he contends that it is challenging to re-create the "organic" and "spontaneous" nature of face-to-face discussion sessions. In face-to-face classes, Charlie explains:

Say you were talking about this idea. "Could you explain this a little further?” And then that bounces to somebody else so you have a sense of what everyone in the classroom has done and what grows out of that is something...like a symphony. And technology gets in the way of that, rather than expediting that. Because when one idea clicks off another and you see people and you see and feel their reactions, there is emotion involved that I don't think is easy to capture online.

In addition to his concerns around face-to-face and online interactions, Charlie also presumes that "it may take longer to develop the trust factor" among the students and between student and teacher. Because his assignments are often structured to push people's thinking on sensitive issues, he takes very seriously the quality of interactions and trust among and with his students.

Beyond concerns around the nature of online versus face-to-face interactions, most participants questioned the academic quality and rigor of online courses. This finding mirrors the results of a recent national survey of approximately 2,500 faculty members and technology administrators which found that $85 \%$ of faculty believe the quality of online courses is lower than face-to-face courses (Jaschik \& Lederman, 2013; see also Herman, 2012) and less than one third of academic officers believe their faculty are accepting of the value and legitimacy of online education (Allen \& Seaman, 2010). Although stating that there are "good things about online teaching," Nolan, the part-time participant who opted out of online teaching, lays out key questions for institutions of higher education:

So a lot of universities are putting stuff online. Is it valid? Is it driven by the buck? Is it something worthwhile? Is it something that is good to do? Well that kind of gets lost in the profitability and revenue because once the revenue comes through, it’s like, "Holy mackerel, look at what we're making here.” ...[T]he [university’s] philosophy could easily get lost someplace...I would want to see valid data, valid statistics that say, "Yes, online training, learning wise and application wise, is as good as the classroom.”

As if reflecting on Nolan's questions, Ben, a participant with face-to-face and online teaching experience, would respond that elements of online education are not as good as the classroom. For example, he questions the rigor of online discussion boards because they "lack critical thinking." As a workaround, Ben assigns simulations and critical reflection papers in which he provides feedback and grades in lieu of discussion boards. Moreover, Ben and others question the students' attention and/or intentions within online courses. In comparing and contrasting his face-to-face and online students, Ben notes "I think it is extremely challenging to get the same quality into the online situation. I don't feel like I can get as much quality time with [the students] because I think they're distracted doing other things and what-not." In agreement, Nolan, the faculty member who has decided to forego online teaching, argues that the type of student drawn to online education is interested in quickly "getting the task done, the course done" and "learning may not necessarily be [his/her] goal."

In sum, five of the seven participants could be described as extremely skeptical about the alignment between their current educational philosophy and practices and/or the academic quality of online education. In the case of one outlier, Thomas, a full-time faculty member with experience teaching 
online courses, shared that he still prefers a face-to-face classroom setting, but as a pragmatist, he remains positive and "makes the best of online education." The second outlier, Leslie, another full-time faculty member, views teaching, whether it is face-to-face or online, through an outcomes approach. "For me," Leslie shared, "online is not different teaching, it uses different tools to work toward the same goal." She recognizes that "online gives you some really good tools" even if it also "makes some things more difficult." Importantly, among the participants of this study, Thomas and Leslie have the most years of experience with online education, and have, in time, grown more comfortable with it. Moreover, both reported the highest levels of sense of community and collegiality around online course development and teaching and have begun utilizing time and dialogue to work through some of their concerns, such that they see possibilities within online education.

Professional identity issues regarding the changing nature of the teaching aspect of professorial work. Second to philosophical questions on the alignment between one's educational philosophy and online education, another key theme in the data concerned participants' perceived identities as teachers. Extant research notes that change, especially role changes and technology, affects professional identity (Glass, 2012; Menzies \& Newson, 2007; Turkle, Gusterson, Dumit, Mindell, \& Silbey, 2005) and increases anxiety among faculty (Maier, 2012). As such, faculty members may struggle with learning a different set of skills for online teaching, especially facilitation skills due to the emphasis on student-directed/self-directed learning within online courses (Palloff \& Pratt 2007). Although many of the participants already shifted from traditional notions of teacher as a "sage on the stage" to more experiential pedagogies, participants still grappled with their identities as teachers in this new format, primarily around the absence of, or reduction in, the "human-to-human interactive elements" they were accustomed to in face-to-face classroom settings. This finding matches previous research highlighting that the loss of face-to-face contact with students is a leading concern among online faculty (Conrad, 2004; McQuiggan, 2012). In the previous section, participants questioned if the lack of live engagement in online education hinders academic quality. Here, participants questioned if they, as teachers, could find meaning and satisfaction in their online coursework without the live interactions. "I would prefer the live [course] because it has all to do with personality and interpersonal interaction," shares Thomas, a full-time faculty member. He continued, "[y]ou [the teacher] get more out of that because of the nature of live versus online." In agreement, Nolan compares the role of the teacher in face-to-face versus online courses: "I love teaching. I'm not sure online is teaching to be honest with you. I think it is a structured syllabus, students teaching and learning on their own, of which you have some guidance.” Thomas and Nolan's concerns around their role as the teacher in online settings agrees with previous work by Glass (2012; 2013) which studies the emotional effects of online teaching on faculty, with an emphasis on how faculty work is a social endeavor in search of meaning. Glass (2013) found that his participants were not "just learning to teach online, they were learning about themselves as a teacher and discovering what they care deeply about as it relates to teaching” (p. 26).

In the case of all but one of the study's participants, faculty-to-faculty interactions around teaching and faculty-to-student interactions in the classroom were areas of dissonance between online teaching and what they care deeply about in relation to their identity as a teacher. Participants talked extensively about their internal struggles with the different role of the teacher in an online course, largely related to the real or perceived loss of interactions with students. As a reoccurring theme in our data, participants do not appear to have an outlet or supportive community to fully reflect on one's transition from a face-to-face to an online paradigm of teacher identity.

\section{Discussion}

Our finding to our first research question - that participants reported wanting a greater sense of community and collegiality around online teaching-did not particularly surprise us based on the literature on faculty work and on the current constraints facing faculty development programs (i.e., 
budgets, personnel, faculty time). However, our findings to our second research question drew more attention: participants primarily desired a sense of community and collegiality around issues related to philosophy and professional identity; issues related to technical skills and pedagogical tools were infrequently mentioned even when prompted in interviews. In other words, it appears participants needed to grapple with the value of online education and their role in this medium of teaching prior to addressing other concerns with online education, such as mastering technology skills or revamping face-to-face lessons for online courses. As such, the nature of participants' needs-alignment between teaching philosophy/professional identity and online education — speaks to a model that promotes dialogue with a community of peers, which unfortunately was not provided for this study's participants despite MU's attempts to support online faculty.

As a case study, MU and our seven participants serve as a reflective example for other institutions and faculty development programs. Due to the qualitative nature of our research and the size of our sample, we do not strive to generalize that our participants' perceptions directly translate to the experiences and needs of all faculty, especially when considering contextual and demographic differences among institutions and faculty members. However, we do believe the insights garnered from our participants - faculty members who expressed an interest in learning more about online education at a university noted for faculty reluctance to online education and with limited resources for online faculty development-highlight two important considerations and reminders for faculty development practice, which we will discuss next.

First, faculty development programs for online education should be guided by faculty members' needs, both in content and in format. Although this suggestion is not new to the field of professional development, many campus programs continue to struggle with low faculty satisfaction levels around online faculty development. We suggest that this disconnect might be related to the challenging and timeconsuming task of uncovering a faculty member's needs around online professional development content and preferred formats, especially in light of the current higher education context of resource scarcity and accountability for action. If campuses hope to ground their online development programs in faculty needs, a commitment on the part of the institution to develop an awareness of online faculty members' needs and a willingness to realign resources to meet those needs is required. For example, one of our participants suggested that he would be better served if MU focused less on adding "bells and whistles" to the course management system that add "slim to [no] value" and instead concentrated their online education budgets and faculty development personnel's time on promoting a sense of community among faculty around the value, shape, and direction of online education at MU. If the goal is faculty buy-in and engagement with the improvement and future of online education, it remains essential that all faculty development programs assess faculty needs and align their resources accordingly.

As mentioned before, it is not an easy task to assess faculty needs and align resources within the complex realities of contemporary higher education. Fortunately, there are exemplary practices across campuses that serve as catalysts for this type of change, including: conducting formal and informal needs assessments of faculty concerns with online education, for example, the Penn State World Campus integrates a self-assessment readiness tool for online faculty (Ragan, Bigatel, Kennan, \& Dillion, 2012); providing opportunities for reflective exercises in which faculty-chosen issues around teaching and learning are explored in communities, for example, the State University of New York's Learning Network explores faculty needs through reflection exercises (McQuiggan, 2012); reviewing exemplary studentreadiness models (that assist students in assessing their own preparedness for online learning) and adapting relevant elements to fit faculty-readiness models (Dray, Lowenthal, Miszkiewicz, Ruiz-Primo, \& Marczynski, 2011; Smith, 2005 ); and developing action research projects that apply faculty data to professional development reforms, to name a few. 
Beyond grounding online professional development in faculty needs, the case of MU and its participants also highlights the need for institutions to support a sense of community and collegiality around online education when applicable. As noted earlier, the extant literature illustrates that despite the benefits of learning communities and the efforts by some institutions to promote them, most faculty report dissatisfaction with their institutions' sense of community and collegiality around online education. As our participants' experiences demonstrate, some topics or concerns held by faculty regarding online education are not conducive to a "one-shot" format or a structure that does not sufficiently build trust and connections among faculty. To engage in the kind of mind-work needed to reflect on issues of philosophy and identity in online education, faculty members need to critically examine and expand upon their perspectives and assumptions about teaching and learning. Research highlights that a sense of community and collegiality is particularly helpful with this type of thinking and transformation (McQuiggan, 2012; Sorcinelli, Austin, Eddy, \& Beach, 2006). To that effect, McQuiggan (2012) writes, "Faculty preparation for online teaching must be conceptualized as a process of transformation rather than simply translation” (p.56).

Although institutions are increasingly offering mentoring and collaborative programming for online faculty, there continues to be room for growth in learning communities, as noted in research highlighting that the most common online faculty development offerings followed a "one-shot" format and the most common content area was the course management system/technical services (Herman, 2012; see also Meyer \& Murrell, 2014). Moreover, private institutions, such as MU, were found to be $20 \%$ less likely to offer mentoring and peer collaborations than public institutions (Meyer \& Murrell, 2014). Again, fortunately there are several exemplary faculty development programs designed to promote a sense of community and collegiality among online faculty that can serve as models that include integrating community building elements into current professional development offerings; initiating cohort models based on a sustained, inquiry-based learning approach; developing orientation and mentoring programs for faculty new to online teaching; creating spaces for sharing examples of faculty members' online courses; facilitating ongoing opportunities for faculty to interact with experienced online colleagues; and providing access to peers' online courses, to name a few (Gappa et al., 2007; Glass, 2012; McQuiggan, 2012). We do acknowledge that all of these efforts require time and resources, which might be scarce in faculty and staff members' schedules and budgets. However, in today's competitive and accountability-driven educational marketplace, institutions that invest in professional development that fosters a sense of community/collegiality around online education, when applicable based on faculty needs, will likely reap rewards in terms of faculty retention, engagement, effectiveness, and productivity.

\section{Concluding Thoughts}

"I think online is definitely the way people are going," reflected one participant, Charlie. He continued: "And I think if we're really serious about online, then we have to be a model to make it the best. So I'm thinking it is the way of the future and we need to not only get on board, but get out front." Although often overlooked, the online course movement is increasingly impacting faculty and their work. Turkle (2004; 2011), a leading scholar on technology-and-the-self, recognizes this impact by noting, "behind every instrumental technology (what the technology does for you), there is another technology, the subjective technology (what the technology does to you)" (2004, p.26). Online education is "doing” something to faculty, and the challenge for faculty development programs on today's campuses is to uncover how online education is impacting faculty (i.e., assessing faculty need) and to develop relevant faculty development programs, both in content and format, based on those needs. If colleges and universities hope to construct online teaching as meaningful academic work rather than something that requires resistance or mere resignation, we believe the effort will be worth the investment. 


\section{Acknowledgements}

We gratefully acknowledge the thoughtful insight and helpful comments provided by Leslie Gonzales and Christopher Glass and the anonymous reviewers on earlier drafts of this manuscript.

\section{References}

Allen, I.E. \& Seaman, J. (2010). Class differences: Online education in the United States, 2010. Needham, MA: Babson Survey Research Group.

Allen, I. E. \& Seaman, J. (2011). Online education in the United States 2011: Going the distance. Newburyport, MA: Sloan Consortium.

Allen, I. E. \& Seaman, J. (2013). Changing Course: Ten Years of Tracking Online Education in the United States. Newburyport, MA: Sloan Consortium.

Brown, J.S., Collins, A., \& Duguid, P. (1989). Situated cognition and the culture of learning. Educational Researcher, 18(1), 32-42.

Conrad, D. (2004). University instructors' reflections on their first online teaching experiences. Journal of Asynchronous Learning Networks, 8(2): 31-44.

Cox, M.D. (2004) Introduction to faculty learning communities. New Directions for Teaching and Learning, 97, 5-23.

Creswell, J.W. (2012). Educational research: Planning, conducting, and evaluating quantitative and qualitative research, 4th edition. Boston, MA: Pearson.

Dolan, V. (2011). The isolation of online adjunct faculty and its impact on their performance. International Review of Research in Open and Distance Learning, $\quad 12(2)$.

Dray, B.J., Lowenthal, P.R., Miszkiewicz, M.J., Ruiz-Primo, M.A., \& Marczynski, K. (2011). Developing an instrument to assess student readiness for online learning: A validation study. Distance Education, 32(1), 29-47.

Erickson, F. (1985). Qualitative methods in research on teaching. In M. Wittrock (Ed.), Handbook of research on teaching, 3rd Ed. (pp. 119-161). New York, NY: Macmillan.

Fulton, K., \& Riel, M. (1999). Professional development through learning communities. Edutopia, 6(2), 8-10.

Gappa, J.M., Austin, A.E., \& Trice, A.G. (2007). Rethinking faculty work: Higher education's strategic imperative. New York, NY: Nolan Wiley \& Sons, Inc.

Gilbert, S. (1995). Teaching, learning and technology: The need for campus wide planning and faculty support services. Change 27(2): 46-52. 
Glass, C.R. (2012). Digitally-mediated teaching and professors' professional worlds and identities: A faculty learning and professional growth perspective. Paper presented at the annual meeting of the Association for the Study of Higher Education, Las Vegas, NV.

Glass, C.R. (2013). Beyond luddites and laggards: The latent social functions that motivate professors to teach (or not teach) online. Manuscript submitted for publication.

Haber, J., \& Mills, M. (2008). Perceptions of barriers concerning effective online teaching and policies: Florida community college faculty. Community College Journal of Research and Practice, 32(4/6), 266-283.

Haviland, D. (2011). Pre-tenure faculty members' experiences and expectations: Challenges, frustrations...and growth. Paper presented at the annual meeting of the Association of the Study of Higher Education, Charlotte, N.C.

Helms, R.M. (2010). New challenges, new priorities: The experience of Generation $X$ faculty. Cambridge, MA: The Collaborative on Academic Careers in Higher Education, Harvard University Graduate School of Education.

Herman, J.H. (2012). Faculty development programs: The frequency and variety of professional development programs available to online instructors. Journal of Asynchronous Learning Networks, 16(5), 87-106.

Hollenshead, C., Waltman, J., August, L., Miller, J., Smith, G., \& Bell, A. (2007). Making the best of both worlds: Findings from a national institution-level survey on non-tenure track faculty. Ann Arbor, MI: Center for the Education of Women.

Jaschik, S. \& Lederman, D. (2013). The 2012 Inside Higher Ed survey of faculty attitudes on technology. Washington DC: Inside Higher Ed.

Kezar, A.J. (2012). Needed policies, practices, and values: Creating a culture to support and professionalize non-tenure track faculty. In A.J. Kezar (Ed.), Embracing non-tenure track faculty: Changing campuses for the new faculty majority. New York, NY: Routledge.

Kinuthia, W. (2005). Planning faculty development for successful implementation of web-based instruction. Campus-Wide Information Systems 22(4): 189-200.

Koehler, M. J., Mishra, P., Hershey, K., and Peruski, L. (2004). With a little help from your students: A new model for faculty development and online course design. Journal of Technology and Teacher Education, 12(1) 25-55.

Lave, J. (1997). The culture of acquisition and the practice of understanding. In D. Kirshner \& J.A. Whitson (Eds.), Situated cognition: Social, semiotic, and psychological perspectives (pp. 63-82). Mahwah, NJ: Erlbaum.

Lu, M., Todd, A.M., \& Miller, M.T. (2011, Fall). Creating a supportive culture for online teaching: A case study of a faculty learning community. Online Journal of Distance Learning Administration, XIV(III).

Maier, L. (2012). What are online teaching faculty telling us about building community? Community College Journal of Research and Practice, 36(11), 884-896. 
McLean, J. (2006). Forgotten faculty: Stress and job satisfaction among distance educators. Online Journal of Distance Learning Administration, 9(2).

McMillan, D., \& Chavis, D. (1986). Sense of community: A definition and theory. Journal of Community Psychology, 14(1), 6-23.

McQuiggan, C.A. (2012). Faculty development for online teaching as a catalyst for change. Journal of Asynchronous Learning Networks, 16(2), 27-61.

Menzies, H., \& Newson, J. (2007). No Time to Think: Academics' life in the globally wired university. Time \& Society, 16(1), 83-98. doi:10.1177/0961463X07074103

Meyer, K.A. \& Murrell, V.S. (2014). A national study of training content and activities for faculty development for online teaching. Journal of Asynchronous Learning Networks, 18(1), 3-18.

Neumann, A. (2009). Professing to learn: Creating tenured lives and careers in the American research university. Baltimore, MD: Nolans Hopkins University Press.

O’Meara, K., Terosky, A. L., \& Neumann, A. (2008). Faculty careers and work lives: A professional growth perspective. ASHE Higher Education Report, 34(3).

Palloff, R.M. \& Pratt, K. (2007). Building online learning communities. San Francisco, CA: Jossey-Bass.

Puzziferro, M.\&., \& Shelton, K. (2009). Supporting online faculty—Revisiting the seven principles (a few years later). Online Journal of Distance Learning Administration, 12(3).

Ragan, L.C., Bigatel, P.M., Kennan, S.S., \& Dillion, J.M. (2012). From research to practice: Towards an integrated and comprehensive faculty development program. Journal of Asynchronous Learning Networks, 16(5), 71-86.

Rice, R.E., Sorcinelli, M.D., \& Austin, A.E. (2000). Heeding new voices: Academic careers for a new generation. New Pathways Working Paper Series (Vol. 7). Washington, D.C.: American Association of Higher Education.

Sarason, S. B., (1974). The psychological sense of community: Prospects for a community psychology. San Francisco, CA: Jossey-Bass.

Seaman, J., (2009). Online learning as a strategic asset. Volume II: The paradox of faculty voices: Views and experiences with online learning, Washington, D.C.: Association of Public and Land-grant Universities.

Sherer, P., Shea, P., \& Kristensen, E. (2003). Online communities of practice: A catalyst for faculty development. Innovative Higher Education, 27(3), 183-194.

Smith, P.J. (2005). Learning preferences and readiness for online learning. Educational Psychology, 25(1), 3-12.

Sorcinelli, M.D., Austin, A.E., Eddy, P.L., and Beach, A.L. (2006). Creating the future of faculty development: Learning from the past, understanding the present. Bolton, MA: Anker Publishing Company. 
Spradley, J. P. (1979). The ethnographic interview. New York: Holt, Rinehart and Winston.

Turkle, S. (2011). Alone together: Why we expect more from technology and less from each other. Cambridge, MA: MIT Press.

Turkle, S. (2004). How Computers Change Way We Think. The Chronicle of Higher Education, B26. Retrieved March 4, 2013.

Turkle, S., Gusterson, H., Dumit, J., Mindell, D., \& Silbey, S. (2005). Information technologies and professional identity: A comparative study of the effects of virtuality. Washington, D.C.: National Science Foundation.

Velez, A.M. (2009). The ties that bind: How faculty learning communities connect online adjuncts to their virtual institutions. Online Journal of Distance Learning Administration, 12(2).

Vogt, W. P., Gardner, D. C., \& Haeffele, L. M. (2012). When to use what research design. Guilford Press.

Vygotsky, L. S. (1978). Mind and society: The development of higher mental processes. Cambridge, MA: Harvard University Press.

Wenger, E. (1999). Communities of practice: Learning, meaning, and identity. Cambridge, MA: Cambridge University Press. 